\title{
A qualitative research of humanitarian workers' perceptions of preventing Gender-Based Violence (GBV) in the Cox's Bazar refugee camps, Bangladesh ${ }^{1}$
}

Una investigación cualitativa de las percepciones de los trabajadores humanitarios sobre la prevención de la violencia de género en los campos de refugiados de Cox's Bazar, Bangladesh

José Navarrete ${ }^{2}$

Universidad de Copenhague, Dinamarca https://orcid.org/0000-0002-9527-8077

\section{Para citar este artículo}

Artículo de investigación

Fecha de recepción: 15 de septiembre de 2018

Fecha de aceptación: 9 de mayo de 2019

Navarrete, J. (2019). A qualitative research of humanitarian workers' perceptions of preventing Gender-Based Violence (GBV) in the Cox's Bazar refugee camps, Bangladesh. Campos en Ciencias Sociales, 7(2), 45-74. DOI: https://doi. org/10.15332/25006681.4670

1. Artículo de investigación desarrollado sobre tesis personal para optar al título de Master of Disaster Management, en la Universidad de Copenhague, Dinamarca.

2. Master of Disaster Management. Correo electrónico: josemiguel.navarrete@hotmail.com 


\section{ACKNOWLEDGEMENTS}

My sincerest gratitude to my supervisor Thilde Rheinländer for her dedication and professionalism. Her support through this process has benefited me considerably and I have learnt a lot from her. Thanks to all the participants in this research. I am grateful for your time and the information you shared with me.

\section{Abstract}

During humanitarian crises, there are priorities to solve immediately such as shelter, food and water. Overcrowding in make-shift settlements and rapid population movement in spontaneous settlements and refugee camps, challenge the capacity of humanitarian workers to implement initiatives to prevent GBV. Forms of GBV can be grouped into four general categories such as sexual abuse, physical abuse, emotional and psychosocial abuse and economic abuse. GBV inflicts harm on women and girls. However, how and when GBV interventions take place? when, will, can those issues become a priority? The main objective of this research is to investigate the experiences of GBV interventions in the Cox's Bazar refugee camps, and how they are perceived by humanitarian workers from different sectors. This is a qualitative interview study, guided by a conceptual framework developed from a literature review on GBV in emergency settings, and the IASC guidelines for integrating GBV interventions in humanitarian action. The data was summarized in a data matrix based on the conceptual framework, and also including emerging issues.

Keywords: GBV in refugee camps, prevention and mitigation of GBV interventions, Rohingya refugee crisis, GBV in emergency settings. 


\section{RESUMEN}

En crisis humanitarias, hay prioridades que resolver de manera inmediata tales como refugio, alimentos y agua. Hacinamiento y sobrepoblación, en asentamientos temporales y en campamentos de refugiados, desafían las capacidades de los profesionales humanitarios para poder implementar iniciativas que prevengan la violencia de género. Algunas formas de violencia de género pueden ser agrupadas en cuatro categorías tales como abuso sexual, abuso físico, abuso emocional y abuso económico. La violencia de género se relaciona directamente con mujeres y niñas. Asimismo, es importante saber cuándo estas intervenciones toman lugar. El objetivo principal de esta investigación es analizar las experiencias sobre intervenciones para prevenir la violencia de género en Cox’s Bazar, campamentos de refugiados, Bangladesh. Esta es una investigación cualitativa donde se llevaron a cabo entrevistas guiadas por un marco conceptual desarrollado a través de la revisión de literatura académica en crisis humanitarias, y las "Directrices para la integración de las intervenciones contra la violencia de género en la acción humanitaria", creadas por Inter-Agency Standing Committee (IASC). Los datos fueron resumidos en una data matriz basada en el marco conceptual, y al mismo tiempo incluyendo asuntos emergentes.

Keywords: prevención y mitigación de violencia de género, Rohingya crisis, violencia de género en campamentos de refugiados, violencia de género en escenarios de emergencia.

\section{INTRODUCCIÓN}

Gender-Based Violence (GBV) is a widespread international public health and human rights concern.

Gender-Based Violence (GBV) is an umbrella term for any harmful act that is made against a person's will and that is based on socially ascribed gender differences between males and females. It includes acts that inflict physical, sexual or mental harm or suffering, threats of such acts, coercion, and other deprivations of liberty (IASC, 2015, p. 5).

Women and girls risk GBV in situations of armed conflict and emergency. Even once they are settled in displacement camps, their individual insecurity often 
increases due to factors such as the breakdown of family and community ties, new threats, and limited access to resources (Freccero, 2015). Attacks related to GBV include female genital mutilation (FGM), domestic violence, forced prostitution/ slavery, rape and other sexual assaults, as well as sexual favors traded for food or aid. Women in uprooted communities such as refugee groups or IDPs groups, are the most vulnerable to GBV (Olsen, 2004). Historically, GBV has been used to link inequalities and abuse of power by males against females to subordinate, punish and control them. Acts of GBV contravene a number of international instruments and conventions and many of the forms of GBV are criminal acts in national laws; however this varies depending on the country, the region and on how laws and policies are implemented (IASC, 2015). The author Merry (2013) states that the human rights system still fails on how to address issues regarding GBV, expressing that the global human rights system, in regards to violence against vulnerable groups, establishes protection to them, however it does so in ways that are often ineffective or unwelcome in practice, and this is transferred to issues of gender equality, where violence is imposed on those most unable to resist. "It is important to remember that GBV is happening everywhere. It is under-reported worldwide, due to fears of stigma or retaliation [...], impunity of perpetrators, and lack of awareness of the benefits of seeking care" (IASC, 2015, p. 2). Additional to the direct harm from violence, GBV has indirect effects such as psychological stress and depression, and GBV may increase the probability of suffering health consequences such as physical disability, chronic pain and chronic diseases such as HIV (Simister, 2011).

\section{GBV in Cox's Bazar refugee camps, Bangladesh}

Since 25 August 2017, almost a million people, and the majority of them women and girls, have fled hostility in Rakhine state, Myanmar, and have crossed the border to Cox's Bazar, Bangladesh, to ask for aid, adding to the 300000 people coming from 1992 to Bangladesh. The people displaced through violence from Myanmar rarely have citizenship and are not recognized as refugees by the Bangladeshi government (IFRC, 2018). "The Rohingya, a minority group from the northern part of Rakhine State (formerly Arakan) in Myanmar, is among the most vulnerable of the world's refugee communities" (Akther and Kusakabe, 2014, p. 225). Root causes of GBV in Cox's Bazar Bangladesh refugee camps are connected with abuse 
of power, disrespect of human rights laws, cultural behaviors in the Rohingya community including gender norms and locally accepted patterns of gender inequality. Factors that may be exacerbated by the lack of lands for site planning including insecure housing conditions, inadequate health and WASH facilities, and no governmental refugee status recognition for the Rohingya communities by the host country. These factors may expose refugees further to GBV acts such as domestic violence, verbal and physical abuse, forced marriage, trafficking and rape. The Rohingya are not recognized as citizens neither by the Myanmar government nor the Bangladeshi government, experiencing discrimination from both nations (Akther and Kusakabe, 2014). Moreover, the Rohingya are not given the status of refugees by the government of Bangladesh. The speed of the influx has resulted in a critical humanitarian crisis, and almost a million of people have crossed the border since last year to look for safety in Cox's Bazar refugee camps, Bangladesh. In this context, many international humanitarian organizations are engaged in supplying aid. This aid includes establishing protection to vulnerable groups. "The Rohingya response is led and coordinated by the Government of Bangladesh, who established a National Strategy on Myanmar Refugees and Undocumented Myanmar Nationals in 2013" (United Nations High Commissioner for Refugees, 2018, p. 34). Some of the sectors in Cox's Bazar and a number of organizations working there are: Health (WHO); Shelter and Settlements (RRRC/IOM/Caritas); Site Management, (RRRC/ IOM/DRC); WASH (UNICEF); Nutrition (UNICEF); Protection (MOWCA/ UNHCR); GBV sub-sector (UNFPA); Logistics \& Telecommunications (WFP), (United Nations High Commissioner for Refugees, 2018). Both the Bangladeshi governmental offices and international organizations are supposed to be working in coordination with the Rohingya communities in Cox's Bazar. However, this can be challenging since many factors obstruct coordination in crisis-affected settings, adding to the large number of actors involved in the humanitarian sector and the Bangladeshi government. Thus, as Balcick, Beamon, Krejci, Muramatsu and Ramírez (2010) state, achieving coordination in the humanitarian sector is critical; so frequently aid organizations in complex settings don't succeed in the effort of coordination, or simply find it too difficult to implement. 


\section{Justification of the research}

The purpose of this research was to investigate for a student's Master thesis the perceptions of humanitarian workers from different sectors of gender based violence (GBV) interventions in the Cox's Bazar refugee camps, in Bangladesh. This focus has been chosen because there is very little knowledge about how staff in camp settings handles GBV in their everyday work, and if these interventions include other humanitarian workers apart from the GBV staff, and how this coordination or inclusion, if existent, play out in the refugee camps. In this sense, the research questions that guide this work are: What are the humanitarian workers' perceptions of interventions to prevent GBV in the Cox's Bazar refugee camps? What challenges do they face in their work?

\section{Methodology}

\section{Overall research approach; Qualitative research}

This research has applied a qualitative approach, and thus based on an interpretive approach to analyze a specific research problem. Within the interpretive approach, a phenomenological analysis has been chosen in which participants in the study describe "what" they experienced with regard to the phenomenon, their experiences of interventions to prevent GBV, and "how" the experienced happened (Creswell, 2007). It is appropriate for this research to investigate perceptions of the humanitarian workers inside the refugee camps in order to be able to understand and discuss which aspects of interventions to prevent GBV may present special challenges for the humanitarian workers to implement, and if there is any coordination playing out inside the refugee camps between the GBV specialists and humanitarian workers from other sectors.

Due to the complexity of the topic, the information given during interviews was kept anonymous and confidential. Interviewees' names and the name of the organization where they work has not been revealed. Nevertheless, rank, positions in the camp and sector they work is mentioned. 


\section{Data collection method: Semi-structured interviews}

In-depth semi-structured interviews were made through Skype with 10 humanitarian workers from different sectors with current or recent experience in the Cox's Bazar refugee camps, Bangladesh. It is generally argued that perception should be analyzed through soft methods such as in-depth interviews (Sjögren, 2000). Semistructured interviews are an appropriate method for this research since the approach of interviewing is open, instead of using a strict set of questions, allowing new ideas as a result of what the participant says, in order to get information focused on the interviewee's experience of a theme.

\section{Selection of study participants}

A strategic sample of study participants was identified for this research, where participants were chosen according to their sector of expertise (WASH, shelter, health, logistics, protection, and camp coordination and camp management) and their work experience in Cox's Bazar refugee camps, Bangladesh. In total 3 of the interviews were conducted in person while the staff was in Copenhagen, Denmark, on the other hand, 7 interviews were conducted over Skype.

Snowball sampling was used, and can happen when one study participant or a group of people recommend new potential participants, thus creating a snowball effect, as explained by the author Chaim Noy in his article "The Hermeneutics of Snowball Sampling in Qualitative Research"(Noy, 2008). The final group of study participants includes 10 professionals from 5 different international humanitarian organizations with recent or current experience in Cox's Bazar refugee camps, having worked there from 5 weeks to more than a year. The majority of them worked or is working in Cox's Bazar refugee camps for less than 5 months.

\section{Data Analysis}

The data analysis was a thematic analysis and the themes came from the conceptual framework, but new themes were included when new issues emerged. The main topics usually derived from the research question, but researchers may discover 
unpredicted topics during their careful reading of the text (Kuckartz, 2014). Therefore, when going through the data and classifying text according to themes, an inductive approach was maintained in which the data was allowed to bring up new themes and issues, adding new perspectives to the data analysis. Qualitative research is often linked to an inductive approach, where usually researchers approach their research objectives without too many predetermined ideas, instead letting the empirical world reveal emerging issues (Kvale and Brinkmann, 2015). Data will be summarized in a data matrix: "In most cases, a profile matrix includes topics (themes) as structuring elements in the columns, so it can also be referred to as a thematic matrix" (Kuckartz, 2014, p. 66).

\section{Prevention and Mitigation of Gender-Based Violence}

The "Guidelines for Integrating Gender-Based Violence Interventions in Humanitarian Action" establish that it is crucial in refugee camp settings to implement actions in order to prevent and mitigate GBV to reduce vulnerabilities. Prevention refers in general to initiatives to stop GBV from first occurring, for instance working with communities, in particular with men and boys in order to promote practices that contribute to gender equality (IASC, 2015). On the other hand, mitigation refers to diminishing the risk of exposure to GBV, for example ensuring that sufficient lighting and security patrols are in place from the onset of a camp setting (IASC, 2015). Those practices, prevention and mitigation, will be mentioned in this research in connection with all the sectors involved in the humanitarian field regarding GBV interventions.

\section{Literature review and developing a conceptual framework}

This research thoroughly reviewed the "Guidelines for Integrating Gender-Based Violence Interventions in Humanitarian Action", which have been revised from the 2005 version by an inter-agency Task Team led by UNICEF and UNFPA, and endorsed by the Inter-Agency Standing Committee (IASC) in 2015. From these guidelines it is possible to identify many areas of investigation regarding prevention and interventions on GBV inside refugee camps. Moreover, the guidelines are 
relevant since it is a portable tool that provides guidance to assist humanitarian actors and affected communities in implementing, monitoring and coordinating essential actions for the prevention of GBV in camp settings, highlighting specific tasks in relation to GBV to all the humanitarian sectors, rather than only focusing on the staff working in GBV. Furthermore, the guidelines recognize that GBV in complex scenarios needs to be confronted from the onset of an emergency by all actors involved including government bodies and donors (IASC, 2015).

Via the literature on GBV in complex emergencies, international reports on the Rohingya situation, and the "Guidelines for Integrating Gender-Based Violence Interventions in Humanitarian Action", this investigation developed a conceptual framework, including all possible areas of investigation for each of the sectors compiled. Lastly, any crossover areas of investigation between sectors were added to the framework as they emerged from literature. E.g. the topic of interventions to prevent GBV in relation to insufficient measures and unexpected consequences emerged from reviewing the article "Assessing refugee camp characteristics and the occurrence of sexual violence: A preliminary analysis of the Dadaab complex", where the authors Aubone and Hernandez state that in Dadaab camp, Kenya, an expensive project to provide fuel sources for the refugees inside the camp was implemented with the purpose of stopping attacks against women when they went to the bush looking for firewood; however this measure proved insufficient, since refugees often travel between camps to visit relatives, or venture into the bush for construction materials (Aubone and Hernández, 2013). In this context it can be mentioned that when implementing a new initiative it is always relevant to analyze and consider negative or unexpected consequences.

\section{Conceptual framework}

From the analysis and review of academic literature on GVB in complex emergencies and the "Guidelines for Integrating Gender-Based Violence Interventions in Humanitarian Action" this investigation has developed a conceptual framework in order to differentiate some of the aspects that might be relevant to investigate interventions to prevent GBV in refugee camps, identifying all the relevant 
humanitarian sectors involved in camp settings, and dividing areas of investigation into specific sectors, and some areas of research concerning all of them.

GBV and its definition has been already mentioned. Other concepts that are relevant for this research are perceptions and sexual violence. Perception as a concept has been linked with subjectivity and personal ideas. The Oxford English Dictionary defines it as "the ability to see, hear, or become aware of something through the senses" (Oxford, 2019). The author Luz Maria Vargas states in her article on perception that one of the disciplines that have analyzed perception as a concept is psychology and the concept is seen as a cognitive process to elaborate an interpretation associated with physical and social environments (Vargas, 1994). On the other hand, sexual violence is defined as:

Any sexual act, attempt to obtain a sexual act, unwanted sexual comments or advances, or acts to traffic, or otherwise directed, against a person's sexuality using coercion, by any person regardless of their relationship to the victim, in any setting, including but not limited to home and work. (Krug, Dahlberg, Mercy, Zwi \& Lozano, 2002, p. 149).

The concept of sexual violence considers a wide range of forms such as sexual harassment; rape by strangers; rape by husband or intimate male partner; rape as a weapon of war in conflict settings; sexual abuse of children; sexual abuse of disable people; forced marriage; forced abortion; female genital mutilation; forced prostitution and human trafficking for the purpose of sexual exploitation (Krug, et al., 2002).

The humanitarian sectors included in the conceptual framework are:

- Camp coordination and camp management (CCCM)

- Protection 


\section{- Education}

- Food \& livelihoods

- Shelter, settlement and recovery (SS\&R)

- WASH

- Health

- Logistics \& telecommunications

After developing the conceptual framework, a corresponding interview guide was developed. The themes are based on the conceptual framework and include six different themes of investigation, with sub-questions.

Main themes:

- Experience of GBV in Cox's Bazaar and the Rohingya population

- Vulnerable groups to GBV in the Cox's Bazar context

- Perception of ongoing protection initiatives

- Perceptions of interventions to prevent GBV

- Unexpected consequences of GBV interventions

- Perception of coordination with authorities and other humanitarian organizations on GBV interventions 


\section{Findings}

This section presents the findings of the qualitative research. The findings are based on a thematic analysis of the interviews. They are presented in 4 sections: 1) GBV in Cox's Bazar refugee camps; 2) Vulnerable groups; 3) Interventions to prevent GBV in Cox's Bazar, and 4) The complexities of coordination in GBV. Moreover, every section presents some subthemes.

\section{1) GBV in Cox's Bazar refugee camps}

This section presents the interviewees' impressions of cultural and gender issues in the Rohingya community that might aggravate GBV in Cox's Bazar refugee camps, Bangladesh.

\section{The Rohingya community culture}

Nine of the interviewees had the impression that there are many GBV cases in the refugee camps; however they said that GBV is not so obvious to identify because the Rohingya community culture is conservative. One participant who works as a psychosocial delegate in Cox's Bazar refugee camps from the beginning of 2018 stated: "firstly, it is something that they don't talk about and secondly, the culture sees this issues as a normal thing happening because it is transgenerational". Another interviewee who works in protection in Cox's Bazar, refugee camps mentioned that: "victims they don't report for many reasons, some of the reasons have to do with their culture, they don't open up and then they don't seek help". This view was supported by another participant who worked as a medical doctor in the health sector for five weeks in 2017. He expressed: "you can see in the Rohingya community conservatism and power imbalance, violence against women...is more accepted". Another participant who worked as a psychosocial delegate for three months in 2018 mentioned: "I know that child marriage is an issue...also bigger now in the refugee camps...it's like... some Rohingya families say about their daughters...we have to marry her off...the situation is very bad so we have to marry her off'. On the other hand, one participant who worked in Cox's Bazar refugee camps for three months in 2018 in shelter and settlements commented on the general question of GBV 
occurrence in Cox's Bazar: "I have no idea...I had no interaction with GBV issues. I was doing shelter and settlements so I was not doing anything medical or anything social”.

\section{Legal status of the Rohingya community in Cox's Bazar refugee camps}

Four participants mentioned that the legal status of the Rohingya community in Bangladesh or even getting an overview of the extent of the problem are core challenges for intervening against GBV. Due to political tensions the Rohingya community has not been assigned refugee status by the government in Bangladesh. This has several consequences for them, including not being allowed to work, and if a GBV case is reported, nothing will really happen to the perpetrators. One interviewee working currently in protection in Cox's Bazar explained that UNHCR is doing a lot of work with the Bangladeshi government in order to recognize the Rohingya community as refugees (Protection delegate). Another interviewee also currently working in protection mentioned: "this is something very challenging, it is complicated because of their legal limitations......they do not have the status of refugees....it is a crisis within a crisis".

The same participant also mentioned that in the camp where this person works there is a big concern by UNHCR, who is the leading protection agency also working with case management, that they do not receive a lot of reports on GBV cases. Even though they expect GBV to happen under the extreme conditions people are experiencing in Cox's Bazar. This was attributed to the conservatism of the Rohingya community as well as the fact that there is no real legal structure that can protect them, and therefore no option to persecute the perpetrators.

\section{Role of community leaders in the refugee camps}

All participants agree that the community leaders -all of them men- have an important role in the Rohingya community, they have a big influence within the society, and therefore are perceived to be key agents in GBV preventions. One of the 
interviewees who worked as a logistic delegate for two months in Cox's Bazar refugee camps in 2018 mentioned: "the community leaders have a lot to say, so if you don't play along with them it's difficult to get things done, because in principle if they don't like the project they can just tell the people to stay out. So you have to get them on board". Another participant who works currently in Cox's Bazar refugee camps as a protection delegate emphasized: "community leaders are not really trained in sensitive issues... so some of them received reports from women being abused by their husbands... and the community leaders threatened the husband...then as a result the husband went back and abused the wife even more". Hence, it seems that community leaders are relevant agents in terms of GBV interventions in Cox's Bazar, and very important to have on board, when trying to start initiatives within the community. Lastly, it seems vital to provide them with training on issues of GBV, human rights and women's rights and how to work with GBV interventions in order to prevent any threats for the community.

\section{Other issues perceived to aggravate GBV in Cox's Bazar, refugee camps}

Most of the interviewees agreed that issues that might exacerbate GBV in the Cox's Bazar refugee camps, include the lack of adequate structural facilities such as latrines and water sources, lack of space, and the threats of natural hazards. One of the interviewees currently working in Cox's Bazar in the WASH sector expressed: “issues that might aggravate GBV are insufficient lightning, lack of safety, inappropriate facilities...they are not gender friendly". Another participant from the protection sector currently working in Cox's Bazar mentioned regarding lighting: "what is happening in the setting of the camps that is quite distressing is the lack of lighting... there is no light at all... it's very bad and you see very few latrines...they are very dirty". One delegate from the health sector who worked in Cox's Bazar for five weeks in 2017, corroborated this: "I think it is completely dark, everything is black". One participant from shelter and settlements who worked in Cox's Bazar for three months in 2018 expressed his concerns about the current monsoon season: "this type of situation makes vulnerable people even more vulnerable". Another interviewee from the protection sector who travels frequently to work in Cox's Bazar explained about the monsoon: "every additional shock where GBV is present is a risk factor... 
in any society, if you add external shocks you will exacerbate dynamics in different ways". Then one participant currently working in Cox's Bazar in the WASH sector stated about the lack of land: "the facilities are inadequate and insufficient...due to the lack of land...". The same participant corroborated the infrastructural problems: "everything that is linked to infrastructure....everything connected with camp management....where to develop community areas...in fact due to the lack of space it's already very difficult to make communal areas...materials are very weak...for instance however protected you might be with a tarpaulin...very limited privacy in the shelters inside the camps....lighting is also a very complicated issue".

To summarize, this data has shown that humanitarian staff working in refugee camps in the Cox's Bazar district agree that simultaneously many dynamics affect and aggravate GBV in this context. Those dynamics include issues such as legal status, conservatism of the Rohingya community, poor structural facilities of the camps, natural hazards, and lack of land. Therefore, the scenario in which GBV should be prevented is highly complex and critical. Most of the participants expressed frustration when trying to engage with interventions to prevent GBV. As a participant currently working as a protection delegate in Cox's Bazar refugee camps stated: "what is happening right now in Cox's Bazar refugee camps... it is a crisis within a crisis".

\section{2) Vulnerable groups}

There was a common perception among most of the interviewees about this topic, and they expressed that girls and women are affected population in this context. Moreover, as many interviewees mentioned, the Rohingya community is very conservative and it is a patriarchal society so the expectations to girls and women are very unequal and rigorous. Some of the interviewees mentioned child marriage as a significant GBV concern within the Rohingya community. One participant currently working as a protection delegate in Cox's Bazar refugee camps reported that: "the most vulnerable groups are first girls and then women.....because girls in particular cannot protect themselves.... and you have also the parents that give the girls for child marriage...because it is the only coping strategy that they have". Another interviewee working regularly in protection in Cox's Bazar mentioned 
that: "there have been many rumors about sexual violence against boys, but no case reported so far".

Other participants mentioned that LGBTI persons might also be at risk of GBV due to the conservatism of the Rohingya community and the host country, Bangladesh (Protection delegate, who travels often to work in Cox's Bazar). One participant from the logistic sector who worked in Cox's Bazar refugee camps for two months in 2018 mentioned: "gays might be at risk of GBV because the culture is very strict..... as far as I remember you can be punished in Bangladesh for being homosexual".

To summarize, this data has shown that women and girls are the affected groups in complex emergencies based on gender inequality. This is confirmed through the thematic analysis in this investigation. Women and girls in Cox's Bazar refugee camps are exposed to GBV due to the factors already mentioned, such as cultural issues, rigorous society models, and power imbalance. Other groups such as men, boys, LGBTI persons can be at risk of sexual violence. However, women and girls are at greater risk of experiencing certain types of violence due to their subordinate position to men in the patriarchal order. For the researcher's lens seems that violence against women and girls is a gendered phenomenon based on gender inequality.

\section{3) Interventions to prevent GBV in Cox's Bazar}

Regarding GBV interventions, most of the participants were aware of and part of some interventions already implemented in the refugee camps. The majority of the participants mentioned that most of the GBV interventions going on in Cox's Bazar included health sector activities such as clinical treatment for victims, emergency PEP (post-exposure prophylaxis to prevent becoming infected with HIV), emergency contraceptives, and psychosocial support for victims of violence. Another GBV intervention mentioned as crucial by most of the interviewees was the handing out of dignity kits, which are packages containing hygiene supplies such as shampoo, soap, sanitary pads and underwear to women and girls. A third important type of GBV intervention mentioned by most participants was child and women friendly spaces. Several participants expressed that there are many of these spaces already implemented. These spaces are focused on providing safe and recreational areas for 
girls and women to spend their free time. Most of these interventions would include the participation of local volunteers.

The type of intervention that was the most perceived by the participants is awareness raising sessions, where professionals and volunteers usually discuss with the Rohingya community different issues concerning their everyday life in the refugee camps. One interviewee from the protection sector currently working in Cox's Bazar expressed her frustration about the difficulties of discussing women's rights as part of these awareness raising sessions: "we are looking to ensure that women are aware of their rights....but it's very difficult what is happening....it's like no one wants to talk about changes of norms, stereotypes, cultural norms". The same participant realized that changing men's attitudes on gender norms should be part of such intervention, but that this was highly difficult to do: "most of the interventions have to do with awareness raising sessions...... and we should involve men in these discussions... we haven't done any awareness sessions with men". Another participant currently working in Cox's Bazar as a psychosocial delegate reported regarding the awareness raising sessions: "it is important to work with the community....to get the information from them.....it is important to not impose something....it is a different culture..... so it is hard to know how to implement discussions on GBV in a very traditional culture... something that is very ah....I would use the word western...but I don't know if it's appropriate". Therefore, the participant agrees that cultural issues may interfere in any initiative on GBV, and at the same time states how relevant it is to work with the community gaining the information from them.

In terms of interventions to prevent GBV, several interviewees mentioned that some organizations such as IOM and UNHCR are working with case management. This starts with filling in referral forms respecting confidentiality of the victims, and then the organizations doing case management are responsible to follow the cases. However, the situation is complex because, as mentioned before, there is no legal status for the refugees. As one of the interviewees currently working as a protection delegate in Cox's Bazar expressed about referrals and case management: "if the referrals go to the organizations doing case management.....they cannot do that much....because there is no legal status for the refugees". The same participant explained about the referral forms: "the referral forms is a form with basic information about the victims who 
are referred...of course beneficiaries have to sign that they consent and that they are familiar with what is written in the referral...we don't put that much information in the referral in order to protect the victims".

\section{Priority of GBV prevention}

An interesting finding about the difficulties of GBV prevention that emerged in the interviews was the issue of 'priority of GBV'. Several participants mentioned that GBV prevention was perceived by the government as a concern to address but the current focus was on the monsoon, a perception shared by humanitarian organizations working in Cox's Bazar. One participant who worked as a psychosocial delegate in Cox's Bazar for three months in 2018 stated regarding case management: "I was in a meeting... and someone like the captain of the Bangladeshi army working with GBV cases in Cox's Bazar.... and he said that GBV will be a topic after the monsoon season"; the same participant then mentioned: "I think UNHCR already prepared some materials in order to start working on GBV mainstreaming after the monsoon". Another participant from protection who travels often to Cox's Bazar for work corroborated this perception: "because all the focus is with the monsoon....so thinking now about trainings on GBV.... it's not the best time... we did that with site management three months ago.....and it was not the best moment to do it...they had so many priorities to solve...to attend... so maybe it was not the best moment". Another interviewee who worked as a psychosocial delegate in Cox's Bazar for 3 months in 2018 stated: "now is the moment when GBV will get attention... so far the focus has been monsoon, monsoon, monsoon".

Most of the interviewees perceived different ideas about challenges. One participant who works as a psychosocial delegate and travels frequently to Cox's Bazar stated about priorities in the work's meetings: "sometimes you go to the health meetings, which I have done in one emergency..... you know you sit there for three hours.... and listen to talk about measles.... and then only two seconds to talk about psychosocial support... and then you realized... psychosocial is not that relevant for them.... but you belong there". Another participant currently working in protection in Cox's Bazar stated on challenges: "it is important to work with the volunteers... 
they need more education... it is essential to improve their capacities". The same interviewee then mentioned about priorities and challenges in Cox's Bazar: "here the humanitarian response is very limited... intensive implementations of programs are very limited....partly because there is no support from the government... when you know that the people for instance they cannot get documentation...they cannot have access to education...they cannot have access to livelihoods... they are basically tracked... and the way out is trafficking". Regarding challenges in Cox's Bazar, another interviewee from the protection sector, who travels often to work in Cox's Bazar, mentioned the principle of confidentiality: "we are always training our staff working in the camps... particularly the ones that are inside the camps $24 / 7 \ldots$ however the Bangladeshi governmental organization working with GBV cases... they want to have access to all cases and they want to have every single GBV case reported... and one of the international principles is confidentiality... so the staff working on GBV are worried about having to provide confidential information to them... it is important to let the specialists work... and not interfere in issues that are far from our roles or expertise".

\section{Unexpected consequences of $G B V$ interventions}

Some of the interviewees expressed that due to the recent massive influx of the refugees in Cox's Bazar (August 2017) it was too soon to discuss negative or unexpected consequences. As one interviewee from the WASH sector currently working in Cox's Bazar stated: "it's too soon to say or talk about negative consequences, the scenario is very recent". Another participant from the protection sector currently working in Cox's Bazar mentioned: "there are no lights in the camps... so there were discussions about having lights by the latrines... so women and girls can go to the toilets without being scared....but what is happening is that men are gathering around the latrines because there is no light in the camps... so then as a result... you have increased cases of GBV". The same participant then mentioned unexpected consequences of handing out 'dignity kits': “you see some men holding dignity kits... which was unexpected... I can imagine some women... for example... that received a dignity kit... and then they exchange them for a little price... because they need some money". 


\section{Mitigation or prevention of $G B V$ ?}

During the interviews, only one participant, who works in protection and travels often to work in Cox's Bazar, made a clear distinction between the two terms of 'mitigation' and 'prevention' of GBV: 'During the interview... we have been talking mostly about interventions to mitigate risks...more than prevention....because there is a big difference between them... mitigation is trying to not exacerbate risks.....but prevention is a topic to work with long-term initiatives....it is really a behavioral change concern....even the awareness raising sessions...they do not generate prevention unless you complement this with an attitude change......we are starting...I know that there is a program called SASA which is very successful in other parts of the world...... and it has a focus on behavioral change which is the only thing that works with prevention....we cannot prevent without a changed behavior".

No other interviewee made this sharp distinction between 'risk mitigation' and 'long-term prevention' but six interviewees did talk about GBV prevention as also including aspects of mitigation, for example when mentioning the importance of raising community awareness and influencing gender norms, as described earlier. One participant working as a psychosocial delegate, who travels frequently to Cox's Bazar to work, stated about interventions to prevent GBV and the rotation of the staff: "short rotation of the staff and volunteers....for GBV the staff should be there on a daily basis to build trust...... I mean...it's so easy to hang up dignity kits.... yes that's great to give the people a bucket and clothes......but it's important to do more....it's all about getting the community itself to discuss....it's more about finding a way with them to do it". Another participant from the health sector, who worked in Cox's Bazar for five weeks in late 2017 expressed about long-term initiatives: "I think understanding the culture is key here.....and might be difficult to understand for us as outsiders....yes I think just talking about sex is difficult.....it's easy to make wrong decisions if you don't really respect the culture".

This part of the analysis has shown that most of the participants had been involved in GBV interventions in Cox's Bazar refugee camps, even if they belong to different sectors than protection. The 'priority' of GBV interventions was brought up by several participant, and it seems that GBV prevention in Cox's Bazar is often 'pushed 
off the daily agenda' by more urgent needs, such as the disaster agenda including the monsoon preparations.

It was also remarkable that a clear distinction between mitigation and prevention was made by only one participant from the protection sector, who explained the urgency of establishing real core prevention programs in order to change the underlying driving factors of GBV, including gender norms, behaviors and attitudes. However, several other participants agreed that this type of 'core prevention' was part of the overall GBV response. There was a consensus among participants that such 'prevention programs' present the 'real challenge' for GBV prevention.

\section{4) The complexities of coordination in GBV interventions}

This section will present how the humanitarian staff experience some of the coordination dynamics between humanitarian organizations, local authorities and within the different sectors on GBV interventions.

\section{External: Coordination between international humanitarian organizations and local authorities}

Some of the participants perceived that the government in charge of the camps also works with GBV. One participant who worked for three months as a psychosocial delegate in 2018 reported: "the army has a role regarding GBV and women could report to them in case of violence against them". Another interviewee, who works in protection and frequently goes to Cox's Bazar to work, mentioned: "the government is starting to be more flexible and supportive with the humanitarian organizations in Cox's Bazar". Another participant who is currently working in protection in Cox's Bazar expressed:"the ministry of women and children affairs...I see little action in terms of projects and programs on GBV....very little....it is the opposite....actually they don't want to talk about these issues..... I haven't seen much coordination.... you see more coordination between the actors... but with the local authorities.... no". Only the participants working in protection and one from the health sector shared some perceptions about the dynamics between international organizations 
and local authorities, and other participants reported that the question was out of their knowledge.

\section{Internal: Coordination on GBV interventions between professionals from different humanitarian sectors working in Cox's Bazar refugee camps}

Most of the participants perceived that their organizations work in protection and GBV mainstreaming. One of the participants, who worked as a logistic delegate for two months in 2018, expressed: "for instance the psychosocial support (PSS) they meet like weekly to discuss...not only about GBV ... and if there is something that we need to be aware of...they will spread the information....it's not that they keep it to themselves...they spread it if there is something the other colleagues from different sectors need to know". The same participant expressed that in 2018 he was part of one training on GBV in his organization at the headquarters office, and there were twenty people in total. He said: "if you see all the participants... we were only two men and eighteen women.....so then we have a problem with the gender diversity”. Another participant who is currently working in Cox's Bazar as a psychosocial delegate mentioned: "yes....in my organization all sectors have the awareness sessions regarding protection.....also as far as I know there are some interagency meetings on the higher level but also directly in the camps....where protection issues are discussed". One participant from the health sector, who worked in Cox's Bazar for five weeks in late 2017 stated about these dynamics: "the interventions that we had were inside the hospital....so we worked definitely with the WASH staff, the psychosocial team, all the health clinical staff, and then the volunteers, they came on the psychosocial support team.....then we actually had a lecture on protection issues at the hospital...so people came and spoke to us about those issues and about GBV". Another interviewee from protection, who is presently working in Cox's Bazar, reported: "In my organization we do Protection, Gender and Inclusion (PGI) mainstreaming...but I haven't heard that much about other organizations....I mean you know....about trainings for other sectors I haven't seen a lot of mainstreaming of protection on GBV". Finally, the interviewee, who belongs to the protection sector and frequently travels to Cox's Bazar, stated: "I don't know how this works in other organizations....inside my organization there are some 
sectors where we have been very successful in terms of collaboration...great work with shelter and site planning.....but from outside the organization there are some challenges....regarding trainings everything is stopped....specially interagency.... because of the monsoon".

Summing up, this part of the analysis has shown that the dynamics in the Cox's Bazar refugee camps connected with coordination are complex. From the participants it was learnt that external GBV coordination was marked by a lack of interaction, a very difficult collaboration, and a challenging sharing of roles and responsibilities with local government. In particular, the lack of legal refugee's status seems to provide humanitarian actors with little options to protect the Rohingya community especially in case management. On the other hand, when talking about internal coordination, most of the participants had experienced that their organizations were engaged in mainstreaming including most of the sectors inside their organizations. Nevertheless, most participants' perception of coordination outside their own organizations it was characterized by no real interaction between humanitarian organizations. They mentioned as well a lack of knowledge about what other organizations are doing in terms of GBV mainstreaming, coordination and inclusion.

\section{DisCUSSION}

\section{Cox's Bazar, vulnerabilities and challenges for GBV interventions}

GBV prevention is indeed perceived to be particularly complex in terms of the context in Cox's Bazar. There are many dynamics simultaneously affecting GBV in Cox's Bazar (social, political, and cultural). It's acknowledged as a problem driven by multiple factors, and challenges exist on multiple levels. Therefore, in emergency scenarios GBV prevention is an area which needs to be managed taking into account a complex mixture of vulnerabilities. This progression of vulnerability is described by the authors Wisner, Blaikie, Cannon \& Davis in their book "At risk" with the pressure and release (PAR) model. Root causes is the first factor in this model, and in the context of Cox's Bazar root causes are connected with gender inequality within the Rohingya community. As the authors state, "dynamic pressures channel the root causes into particular forms of unsafe conditions" (Wisner et al., 2004, p. 54). 
Regarding Cox's Bazar, dynamic pressures are connected with the current conflict between the Rohingya community and Myanmar. Concerning unsafe conditions, they are described as "the specific forms in which the vulnerability of a population is expressed in time and space in conjunction with a hazard" (Wisner et al., 2004). And brought to the context of Cox's Bazar, connected to issues such as the lack of land and poor structural facilities of the camps. Then, natural hazards are also present in this context, and as mentioned throughout this investigation, since the monsoon season is due to cause flooding and landslides, most of the humanitarian response is focused on it. Thus, all these factors aggravate the circumstances for the Rohingya community, and make them more vulnerable to experience GBV. Therefore, interventions to prevent GBV may not be the first priority to solve in those scenarios.

However, the findings in this study context indicate that the very complex mixture of vulnerabilities for GBV in the Cox's Bazar refugee camps is not likely to be extraordinary. It is likely that risks and vulnerabilities for GBV are similar in other contexts (refugee camps) around the globe, such as in the Kakuma refugee camp, Kenya, where composite factors also aggravated the situation for the refugees, such as lack of livelihoods, the loss of roles and status, and the impact of conflict and displacement affecting every aspect of their lives (Horn, 2010). This means that the specific context of Cox's Bazar may be unique but in terms of the compositeness of vulnerabilities not exceptional, and in every crisis-affected setting there will be multiple vulnerabilities to be addressed.

\section{Dilemmas of 'priority' and of doing 'prevention' or 'mitigation' of GBV}

One of the interesting aspects that has emerged from this research is regarding the perceptions of GBV as a 'low priority' area during emergencies, and of the distinctions made between short-term mitigation and long-term prevention. This research found a necessity of new types of programmes to really change gender norms and behaviors, and to find long-term solutions in prevention of GBV rather than continuing with short-term risk mitigation initiatives. From this thesis it does seem vital to implement initiatives on changing community and gender norms through engaging people in a more strategic way in order to thoroughly tackle the social and cultural issues driving GBV. 
But at the same time one can ask: is it really possible to do time consuming and long-term GBV prevention in highly complex emergencies? It seems very difficult to address GBV interventions in complex settings when there are many other more acute and life-saving priorities and needs to tend to, such as shelter, safety, food and water. The situation regarding education in complex settings may be similar. In its article regarding the exigency of education, the Education Cluster expresses that the global funding for education in humanitarian crises has declined since 2010, corroborating that globally, education receives very small funds compared to other sectors in the humanitarian field, thus recognizing education as 'low priority' in times of emergencies (Sparkes, Kalmthout and Martínez, 2013). The same argument can be found in the Save the Children report on "What the children want in time of emergencies; They want education" stating that education is frequently underprioritized in emergencies, and underfunded by donors, which has left million of children in crisis-affected settings without education (Save the Children, 2015).

\section{Coordination dynamics}

Coordination of GBV interventions was perceived by humanitarian staff to be highly complex. Firstly, internal coordination among sectors is marked by lack of interaction and lack of knowledge about what other organizations are doing in Cox's Bazar. This is also mentioned in the articles "Coordination in humanitarian relief chains: practices, challenges and opportunities" and "Coordination in humanitarian relief chains; chain coordinators", where the authors mention that achieving coordination in the humanitarian sector is acknowledged as critical because each of the organizations have different interests, mandates and competences, nevertheless no single actor has the capacity to respond independently to a crisis (Balcik et al., 2010; Akhtar, Marr and Garnevska, 2012). Hence, it's vital to promote participation and inclusion between organizations when working in crisis-affected settings in order to further reduce the risk of issues such as GBV. Moreover, the amount of stakeholders in Cox's Bazar is enormous, as stated in the UN report on the Rohingya humanitarian crisis, expressing that with such a large set of actors currently in Cox's Bazar adding to the pressure of the setting, only effective coordination will ensure efficient use of resources (United Nations High Commissioner for Refugees, 2018). 
On the other hand, time and efficiency should be taken into account when working in an emergency context, and excessive bureaucracy may affect aid efforts negatively. As Balcik et al. reported about coordination in the United Nations (UN) after the 2004 Asian tsunami. The UN failed to ensure a general coordination among the sectors involved, and UN agencies organized numerous coordination meetings without clear purposes and since the meetings were in English without translation, most of both the local and international organizations stopped attending the meetings (Balcik et al., 2010).

In terms of external coordination, GBV interventions in Cox'sBazar were marked by the lack of interaction and a very complex sharing of roles and responsibilities with the Bangladeshi government. Coordination has to go beyond just a large amount of meetings between the government and the humanitarian sector. Efficient and effective external coordination depends also on working with the host government in trying to recognize the rights of the communities in need, if those are not in place. In the context of Cox's Bazar, the lack of the refugee's legal status, and the lack of possibilities for the refugees to work, indeed aggravate their situation. As Krause states in her article about the continuum of violence between sexual and gender based violence during conflicts, flights and encampment in Uganda, "Insufficient law enforcement was continuously mentioned by refugees as a great obstacle with regard to sexual and gender-based violence and beyond" (Krause, 2015, p. 14). Insufficient law enforcement and lack of refugee status recognition are also interlinked with lack of livelihood opportunities of the Rohingya community and ineffective punishment for the perpetrators in case of GBV attacks.

\section{ConClusion}

Gender-Based Violence is among the greatest protection challenge that individuals, families and communities face during humanitarian emergencies. Women and girls are the ones affected particularly in emergency settings. Nevertheless, other groups such as men, boys, LGBTI people, can be at risk of sexual violence. However, since GBV is based on the relation of power imbalance between men and women; for the researcher seems that those groups should not be under the GBV umbrella. Given these differences, it is important to advocate and work in coordination with 
other sectors focused on different types of violence such as violence against LGBTI persons and violence experienced by men. It seems that addressing gender inequality is essential for efficient GBV interventions. Since GBV is a gendered phenomenon associated with gender inequality as a root cause, it is crucial to keep women and girls at the focus of GBV programmes to tackle the root causes of violence: gender inequality, power imbalance and the way these factors shape individual, community behaviors and norms.

This qualitative research has shown that most of the interviewees had been involved in GBV interventions in the Cox's Bazar refugee camps, even if they belong to different humanitarian sectors than protection. As learned through this research, many factors affect and aggravate GBV. Those factors include issues such as legal status, conservatism of the Rohingya community, poor structural facilities of the camps, natural hazards and lack of land.

The 'priority' of GBV interventions was brought up by several participants, and it seems that GBV prevention in Cox's Bazar is often 'pushed off the daily agenda' by more urgent needs such as the response to the monsoon. Similar to GBV, globally other issues, such as education have been deferred in emergency settings.

Regarding 'risk mitigation' and 'prevention', it seems crucial to implement longerterm prevention programs in order to effectively change the underlying driving factors of GBV, including gender norms, behaviors and attitudes, rather than sticking perpetually by risk mitigation interventions on emergency settings.

It appears very difficult to address GBV interventions in emergency settings when there are other priorities to solve immediately. Other factors may impede the already complex scenario. The analysis has shown that the dynamics of internal and external coordination in relation to GBV interventions in the Cox's Bazar refugee camps are complex. In this context, the Bangladeshi government has the official responsibility and decision-making power, and the humanitarian actors in Cox's Bazar only their good intentions to protect the community in need. 
Finally, this research suggests further investigation into programs regarding longerterm GBV interventions in crisis-affected settings.

\section{REFERENCIAS}

Akhtar, P., Marr, N. E., \& Garnevska, E. V. (2012). Coordination in humanitarian relief chains: chain coordinators. Journal of Humanitarian Logistics and Supply Chain Management, 2(1), 85-103. DOI: 10.1108/20426741211226019

Akhter, S., \& Kusakabe, K. (2014). Gender-based Violence among Documented Rohingya Refugees in Bangladesh. Indian Journal of Gender Studies, 21(2), 225-246. DOI: $10.1177 / 0971521514525088$

Aubone, A., \& Hernández, J. (2013). Assessing refugee camp characteristics and the occurrence of sexual violence: A preliminary analysis of the dadaab complex. Refugee Survey Quarterly, 32(4), 22-40. DOI: 10.1093/rsq/hdt015

Balcik, B., Beamon, B. M., Krejci, C. C., Muramatsu, K. M., \& Ramírez, M. (2010). Coordination in humanitarian relief chains: Practices, challenges and opportunities. International Journal of Production Economics, 126(1), 22-34. DOI: 10.1016/j. ijpe.2009.09.008

Creswell, J. W., \& Poth, C. N. (2007). Qualitative inquiry and research design: Choosing among five approaches. London, UK: SAGE.

Freccero, J. (2015). Sheltering displaced persons from sexual and gender-based violence. Forced Migration Review, (50), pp. 55-58.

Horn, R. (2010). Exploring the impact of displacement and encampment on domestic violence in Kakuma refugee camp. Journal of Refugee Studies, 23(3). DOI: 10.1093/jrs/ feq020 
IASC. (2015). 'Guidelines for Integrating Gender-based Violence Interventions in Humanitarian Action', Response, (September), pp. 1-366. Available at: http:// gbvguidelines.org/wp-content/uploads/2015/09/2015-IASC-Gender-based-ViolenceGuidelines_lo-res.pdf

IFRC. (2018). 6 months review and mid-term planning mission for the Bangladesh Population Movement Operation for PSS in the Japanese Red Cross Society ERU. Ea Akasha, technical advisor, IFRC Reference Centre for Psychosocial Support and Eri Tayama, PSS Focal Point, Japanese Red Cross Society

Kuckartz, U. (2014). Qualitative text analysis. A guide to methods, practice \& using software. London, UK: Sage Publications Ltd.

Krause, U. (2015). A Continuum of Violence? Linking Sexual and Gender-based Violence during Conflict, Flight, and Encampment. Refugee Survey Quarterly, 34(4), 1-19. DOI: $10.1093 / \mathrm{rsq} / \mathrm{hdv} 014$

Krug, E. G., Dahlberg, L. L., Mercy, J. A., Zwi, A. B., \& Lozano, R. (2002). World report on violence and health. Genova, Italy: World Health Organization

Kvale, S., \& Brinkmann, S. (2015). Interviews: Learning the craft of qualitative research interviewing. London, UK: Sage publications, Inc.

Merry, S. E. (2013). Human Rights and Gender Violence. Journal of Chemical Information and Modeling, 53(9), 1689-1699. DOI: 10.1017/CBO9781107415324.004

Noy, C. (2008). Sampling knowledge: The hermeneutics of snowball sampling in qualitative research. International Journal of Social Research Methodology, 11(4). DOI: $10.1080 / 13645570701401305$.

Olsen, O. E., \& Scharffscher, K. S. (2004). Rape in refugee camps as organisational failures. The International Journal of Human Rights, 8(4), 377-397. https://doi. org/10.1080/1364298042000283558 
Oxford English Living Dictionaries. (2019). Definition of perception. Recovered from https://en.oxforddictionaries.com/definition/perception

Save the Children. (2015). What do children want in times of emergency and crisis? They want an education. London, UK: Save the Children.

Simister, J. (2014). Gender-Based Violence. Causes and remedies. New York: Nova Science publishers, Inc.

Sjögren, L. (2000). The Methodology of Risk Perception Research. Quality \& Quantity, 4(4), 407-418.

Sparkes, J., Kalmthout, van E., \& Martínez, E. (2013). Education Cannot Wait Humanitarian Funding is Failing Children. Humanitarian Response: Education Cluster. Recovered from http://education.humanitarianresponse.info/document/ education-cannot-wait-humanitarian-funding-failing-children

United Nations High Commissioner for Refugees. (2018). Jrp for Rohingya. Humanitarian Rights, March-December 2018. Recovered from http://reporting.unhcr.org/sites/default/ files/JRP\%20for\%20Rohingya\%20Humanitarian\%20Crisis\%20-\%20March\%20 2018.PDF

Vargas Melgarejo, L. M. (1994). Sobre el concepto de percepción. Alteridades, 4(8). Recuperado de http://biblioteca.ues.edu.sv/revistas/10800277-4.pdf

Wisner, B., Blaikie, P., Cannon, T., \& Davis, I. (2004). At Risk, natural hazards, people's vulnerability and disasters. London, UK: Routledge. 